\title{
PERBEDAAN KEKASARAN PERMUKAAN BASIS RESIN AKRILIK POLIMERISASI PANAS MENGGUNAKAN BAHAN PUMIS, CANGKANG TELUR DAN PASTA GIGI SEBAGAI BAHAN POLES
}

\author{
Syafrinani*, Yudi Setiawan** \\ * Departemen Prostodonsia Fakultas Kedokteran Gigi Universitas Sumatera Utara, \\ ** Mahasiswa Fakultas Kedokteran Gigi Universitas Sumatera Utara \\ ydisetiawan@gmail.com
}

\begin{abstract}
Denture base widely were made from heat polymerized acrylic resin. Either one of physical properties on this material must be concern is surface roughness, rough surface could interfere patient's comfort, and microbial colonization. Therefore polishing procedure were needed, polishing material that mostly used on acrylic resin was pumice, there is another alternative material i.e eggshell and toothpaste because had abrasive ability. The aim of this research is to determine the difference surface roughness of heat polymerized acrylic denture base resin used pumice, eggshell and toothpaste as polishing materials. The design research in this study is laboratory experimental with rectangle sample with size $50 \times 20 \times 3 \pm 1 \mathrm{~mm}$. There are 30 samples for 3 groups. The result of this research shows a significant difference between pumice group and eggshell group with $p$ value $=0,0001(p<0,05)$, pumice and toothpaste with $p$ value $=0,0001$ ( $p$ $<0,05)$, egghsell and toothpaste with $p$ value $=0,032(p<0,05)$. Polishing that used an alternative material from eggshell and toothpaste produce lower surface roughness score rather than pumice.
\end{abstract}

Keywords : Heat polymerized acrylic resin, denture base, surface roughness, polishing materials

\section{PENDAHULUAN}

Sejak ditemukan pada tahun 1937, resin akrilik polimerisasi panas (RAPP) merupakan bahan yang paling banyak digunakan untuk membuat basis gigi tiruan oleh karena harga yang murah, mudah dimanipulasi, direparasi dan mudah untuk dipoles. ${ }^{1-3}$ Salah satu sifat RAPP yang perlu diperhatikan adalah sifat fisis yaitu kekasaran permukaan, hal ini dikarenakan kekasaran permukaan merupakan faktor penting yang mempengaruhi secara langsung terhadap kenyamanan pasien, retensi plak bakteri dan stain. ${ }^{3}$ Bollen dkk. (1997) menyarankan gigi tiruan serta restorasi gigi tidak boleh memiliki nilai kekasaran permukaan lebih dari $0,2 \mu \mathrm{m} .{ }^{4}$ Agar mengurangi nilai kekasaran permukaan, maka perlu dilakukan proses pemolesan. ${ }^{3}$ Pemolesan resin akrilik umumnya dilakukan secara mekanis dengan menggunakan bahan abrasif karena menghasilkan permukaan yang lebih halus. Bahan abrasif yang paling banyak digunakan sebagai bahan poles untuk resin akrilik adalah pumis. ${ }^{5,6}$ Pumis berasal dari bebatuan vulkanik yang memiliki pori-pori terbentuk akibat erupsi, memiliki tekstur kasar yang terdiri dari silika $\left(\mathrm{SiO}_{2}\right)$ 60$75 \%$, alumina $\left(\mathrm{Al}_{2} \mathrm{O}_{3}\right)$ 13-17\%, sodium oksida-potasium oksida $\left(\mathrm{Na}_{2} \mathrm{O}-\mathrm{K}_{2} \mathrm{O}\right) 7-8 \%$, dan sedikit iron oksida $\left(\mathrm{Fe}_{2} \mathrm{O}_{3}\right)$, kalsium oksida $(\mathrm{CaO})$, tin oksida $\left(\mathrm{TiO}_{2}\right){ }^{7}$

Bahan alternatif lain yang bersifat abrasif serta berpotensi sebagai bahan poles RAPP adalah cangkang telur dan pasta gigi. ${ }^{4,8}$ Oleh karena kandungan calcite pada kalsium karbonat menjadikan cangkang telur bersifat abrasif, kandungan tertinggi kalsium karbonat terdapat pada cangkang telur ayam $(70,84 \%)$, sehingga telah dimanfaatkan sebagai bahan dasar pembuatan kertas abrasif, roda amplas serta bahan abrasif pada pasta gigi. ${ }^{79}$ Onwubu dkk. (2016) menyatakan calcite pada kalsium karbonat yang berasal dari cangkang telur yang dihaluskan memiliki sifat abrasif dan dapat memoles permukaan basis gigi tiruan resin akrilik.?

Pasta gigi umumnya digunakan untuk permukaan gigi dan pembersih mekanis gigi tiruan, oleh karena memiliki efek pemolesan, pasta gigi memiliki keuntungan untuk mengurangi akumulasi plak bakteri karena mengurangi kekasaran permukaan pada gigi. Kandungan bahan abrasif pada pasta gigi dapat berupa kalsium karbonat, sodium bikarbonat, perlite serta silika yang efek abrasif pasta gigi tergantung dari banyaknya bahan tersebut. Umumnya bahan abrasif pada pasta gigi sekitar 20-55\% dari total beratnya. ${ }^{8}$ Tarbet dkk. (1984) menyatakan pasta gigi yang memiliki tingkat abrasif rendah dapat memoles permukaan gigi tiruan. Pisani dkk. (2010) setelah melakukan percobaan pengaruh tingkat abrasif pada pasta gigi terhadap kekasaran permukaan resin akrilik, menyatakan pasta gigi yang memiliki kandungan silika memiliki efek pemolesan pada permukaan basis gigi tiruan. ${ }^{10}$ 
Berdasarkan hal teresebut timbul pemikiran untuk memanfaatkan cangkang telur ayam dan pasta gigi sebagai bahan poles basis resin akrilik polimerisasi panas.

\section{BAHAN DAN METODE}

Penelitian ini merupakan penelitian eksperimental laboratoris. Cangkang telur yang akan diolah dikumpulkan dari berbagai tempat penjualan makanan, dicuci dengan air mengalir lalu direndam dengan larutan sodium hipoklorit $2,5 \%$ selama 6 jam. Bahan dikeringkan menggunakan oven listrik (Nabertherm, USA) selama 6 menit dengan suhu $250{ }^{\circ} \mathrm{C}$. Penambahan zat sodium lauryl surfaktan $15 \mathrm{~g}$ ke $300 \mathrm{~g}$ cangkang telur kemudian di blender hingga homogen. Penggunaan ball-mill (Retsch PM 200 Series, Germany) agar mendapatkan ukuran partikel yang halus dilakukan selama 60 menit dengan kecepatan $400 \mathrm{rpm}$. Bubuk kemudian disaring dengan saringan laboratorium mesh 400 .

Sampel dibuat dari resin akrilik polimerisasi panas ukuran 50 × 20 × $3 \pm 1 \mathrm{~mm}^{4}$ Jumlah keseluruhan sampel adalah 30 sampel dan dibagi menjadi 3 kelompok yaitu kelompok A pumis, kelompok B cangkang telur, dan kelompok $\mathrm{C}$ pasta gigi. Kuvet yang berisi mold berasal dari model induk yang ditanam pada gips, Mold di isi dengan adonan resin akrilik kemudian kuvet ditutup dan dilakukan kuring di dalam waterbath. Sampel dikeluarkan dari kuvet dan dirapikan dengan bur fraser, dihaluskan dengan kertas pasir waterproof ukuran 400, 800, 1200 yang dipasangkan pada rotary grinder dengan air mengalir masing-masing selama 5 menit dan dilanjutkan dengan pemolesan menggunakan polishing motor yang dipasang ragwheel, dengan menggunakan bahan pumis untuk kelompok A, bubuk cangkang telur untuk kelompok B dan pasta gigi untuk kelompok C. Masing-masing sampel dipoles selama 2 menit.

Pengujian kekasaran permukaan dilakukan dengan menggunakan alat ukur profilometer. Analisis data dilakukan dengan uji Univarian dan uji ANOVA satu arah.

\section{HASIL}

Hasil penelitian menunjukkan nilai rerata kekasaran permukaan yang dianalisis dengan menggunakan uji Univarian yaitu pada kelompok A dengan nilai rerata $0,102 \mu \mathrm{m}$ dengan standar deviasi 0,016. Nilai rerata kelompok B adalah 0,059 $\mu \mathrm{m}$ dengan standar deviasi 0,008 . Nilai rerata kelompok $\mathrm{C}$ adalah 0,088 $\mu \mathrm{m}$ dengan standar deviasi 0,015 (Tabel 1).

Tabel 1. Nilai kekasaran permukaan basis resin akrilik polimerisasi panas setelah dipoles dengan bahan pumis, cangkang telur dan pasta gigi

\begin{tabular}{c|c|c|c}
\hline \multirow{2}{*}{ No } & \multicolumn{3}{|c}{ Kekasaran Permukaan $(\mu \mathrm{m})$} \\
\cline { 2 - 4 } & Kelompok A & Kelompok B & Kelompok C \\
\hline 1 & 0,118 & 0,064 & 0,102 \\
\hline 2 & $0,122^{*}$ & 0,051 & 0,081 \\
\hline
\end{tabular}

\begin{tabular}{c|c|c|c}
\hline 3 & 0,104 & 0,064 & 0,071 \\
\hline 4 & 0,090 & 0,050 & 0,074 \\
\hline 5 & $0,074^{* *}$ & 0,060 & 0,088 \\
\hline 6 & 0,103 & 0,059 & $0,064^{* *}$ \\
\hline 7 & 0,079 & $0,073^{*}$ & 0,097 \\
\hline 8 & 0,104 & 0,066 & $0,111^{*}$ \\
\hline 9 & 0,108 & $0,047^{* *}$ & 0,102 \\
\hline 10 & 0,121 & 0,058 & 0,092 \\
\hline & $\overline{\mathrm{X}}=0,102$ & $\overline{\mathrm{X}}=0,059$ & $\overline{\mathrm{X}}=0,088$ \\
& $\mathrm{SD}=0,016$ & $\mathrm{SD}=0,008$ & $\mathrm{SD}=0,015$ \\
\hline
\end{tabular}

Keterangan : * nilai terbesar

** nilai terkecil

Berdasarkan uji ANOVA satu arah didapatkan adanya perbedaan nilai kekasaran permukaan yang signifikan pada ketiga kelompok tersebut dengan nilai $\mathrm{p}=$ $0,0001(\mathrm{p}<0,05)($ Tabel 2).

Tabel 2. Hasil uji ANOVA terhadap nilai kekasaran permukaan antara kelompok pumis, cangkang telur dan pasta gigi sebagai bahan poles

\begin{tabular}{c|c|c|c}
\hline \multirow{2}{*}{ Kelompok } & \multicolumn{3}{|c}{ Kekasaran Permukaan $(\mu \mathrm{m})$} \\
\cline { 2 - 3 } & $\mathrm{n}$ & $\overline{\mathrm{X}} \pm \mathrm{SD}$ & $\mathrm{p}$ \\
\hline $\mathrm{A}$ & 10 & $0,102 \pm$ & \\
& & 0,016 & \\
\hline $\mathrm{B}$ & 10 & $0,059 \pm$ & \multirow{2}{*}{$0,0001^{*}$} \\
& & 0,008 & \\
\hline $\mathrm{C}$ & 10 & $0,088 \pm$ & \\
& & 0,015 & \\
\hline
\end{tabular}

Keterangan : * signifikan

Berdasarkan uji LSD (least significant difference) memperoleh nilai kekasaran permukaan antara kelompok A dengan kelompok $\mathrm{B}$ dengan nilai $\mathrm{p}=$ 0,0001 ( $\mathrm{p}<0,05)$, kelompok A dengan kelompok $\mathrm{C}$ dengan nilai $\mathrm{p}=0,032(\mathrm{p}<0,05)$, kelompok $\mathrm{B}$ dengan kelompok $\mathrm{C}$ dengan nilai $\mathrm{p}=0,0001(\mathrm{p}<0,05)($ Tabel 3$)$.

Tabel 3. Hasil uji LSD pada masing-masing kelompok

\begin{tabular}{c|c}
\hline Kelompok & $\mathrm{p}$ \\
\hline A dengan B & $\mathrm{p}=0,0001^{*}$ \\
\hline A dengan C & $\mathrm{p}=0,0001^{*}$ \\
\hline B dengan C & $\mathrm{p}=0,032^{*}$ \\
\hline
\end{tabular}

Keterangan : * signifikan

Hasil penelitian menunjukkan ketiga kelompok memiliki nilai kekasaran permukaan dibawah nilai ideal yang diterima dibidang kedokteran gigi yaitu 0,2 $\mu \mathrm{m}$. Berdasarkan hasil uji statistika menunjukkan kelompok B memiliki nilai kekasaran permukan yang lebih kecil dibandingkan kelompok A dan kelompok C. Terdapat perbedaan bermakna antara kelompok B dengan kelompok A dan $\mathrm{C}$. 


\section{PEMBAHASAN}

Hasil penelitian menunjukkan nilai kekasaran permukaan yang bervariasi pada setiap sampel dalam satu kelompok yang sama. Hal ini dapat disebabkan oleh penekanan sampel saat dilakukan penghalusan dan pemolesan pada alat rotary grinder dan polishing motor. Setiap sampel mendapatkan tekanan yang berbeda selama pemolesan oleh karena dilakukan secara manual menggunakan tangan operator. Adanya perbedaan tekanan ini akan mengakibatkan perbedaan tinggi puncak dan lembah dari alur yang terbentuk pada garis pemolesan. Apabila tekanan sedikit diberikan, maka akan mengakibatkan pengikisan pada permukaan bahan tidak terjadi secara menyeluruh, akan tetapi apabila tekanan yang diberikan besar, maka semakin banyak bagian dari puncak dan lembah alur yang terbuang sehingga rerata kekasaran permukaan yang dihasilkan akan semakin kecil bahkan apabila tekanan terlalu besar dapat menyebabkan pengikisan yang terlalu berlebihan pada permukaan bahan. Pengukuran kekasaran permukaan dilakukan sebanyak tiga kali. Hasil yang didapatkan dari pengukuran pertama, kedua, dan ketiga pada setiap sampel yang sama menunjukkan nilai yang berbeda. Hal ini dapat disebabkan oleh adanya perbedaan garis yang dilewati stylus pada setiap pengukuran. Setiap pengukuran, stylus melewati garis yang berbeda dengan kedalaman alur yang berbeda juga, dimana semakin dalam alur yang terbentuk yang dilewati stylus setelah pemolesan maka nilai kekasaran permukaan yang dihasilkan akan semakin besar.

Berdasarkan data yang diperoleh pada tabel 1, nilai kekasaran permukaan pada kelompok A yaitu sebesar $(0,102 \pm 0,016 \mu \mathrm{m})$. Nilai kekasaran permukaan kelompok B $(0,059 \pm 0,008 \mu \mathrm{m})$. Nilai kekasaran permukaan kelompok C $(0,088 \pm 0,015 \mu \mathrm{m})$. Dari hasil uji ANOVA satu arah pada tabel 2 terlihat bahwa ada perbedaan bermakna minimal pada dua kelompok karena diperoleh signifikansi $\mathrm{p}=0,0001(\mathrm{p}<0,05)$.

Kelompok A memiliki nilai kekasaran permukaan dibawah nilai kekasaran ideal yang diterima dibidang kedokteran gigi. Kelompok A yang diberi perlakuan pemolesan dengan pumis memiliki nilai rerata kekasaran permukaan $0,102 \pm 0,016 \mu \mathrm{m}$, nilai ini tidak jauh berbeda dengan penelitian sebelumnya yang memiliki nilai rerata kekasaran permukaan $0,130 \pm 0,03 \mu \mathrm{m} .{ }^{4}$ Hanna BA dkk. (2008) menyatakan pumis dapat menghasilkan nilai kekasaran permukaan yang berbeda-beda, oleh karena komposisi yang bervariasi tergantung persentase kandungan mineral silika yang berkisar 60\% - 67\%, sehingga dapat mempengaruhi sifat abrasif bahan tersebut. ${ }^{11}$

Kelompok B yaitu kelompok yang diberi perlakuan pemolesan dengan bubuk cangkang telur, memiliki nilai rerata kekasaran permukaan 0,059 $\pm 0,008$ $\mu \mathrm{m}$, nilai rerata ini tidak jauh berbeda dengan nilai rerata penelitian sebelumnya. Onwubu SC dkk. (2016) memperoleh nilai kekasaran permukaan resin akrilik setelah dipoles menggunakan bubuk cangkang telur memiliki nilai rerata $0,069 \pm 0,014 \mu \mathrm{m}^{4}$ Perbedaan yang terdapat pada penelitian ini dengan penelitian sebelumnya adalah saat pemrosesan bubuk cangkang telur. Penelitian sebelumnya, dalam pemrosesan penggilingan dengan menggunakan ball-mill dilakukan selama 40 menit, sedangkan pada penelitian ini menggunaan ball-mill dilakukan selama 60 menit. Wu SC dkk. (2015) menyatakan penggilingan cangkang telur dengan menggunakan ball-mill selama 60 menit dapat menghasilkan rerata ukuran partikel 2,21 $\mu \mathrm{m} .{ }^{12}$ Berdasarkan penelitian tersebut dapat diketahui semakin lama waktu penggilingan dengan ball-mill dapat menghasilkan ukuran partikel yang semakin kecil. Selain tekanan saat pemolesan, faktor lain yang dapat mempengaruhi nilai kekasaran permukaan adalah ukuran partikel bahan pemoles, ukuran partikel bahan pemoles yang kecil memiliki kelebihan berupa dapat menghasilkan nilai kekasaran permukaan yang rendah. ${ }^{13}$ Penggunaan pemegang sampel juga mempengaruhi hasil nilai kekasaran permukaan, oleh karena sampel yang menggunakan pemegang mendapatkan pemolesan yang merata disetiap bagian. Hal ini dapat dilihat dari hasil rerata sampel kelompok B pada penelitian ini yang memiliki nilai $0,059 \mu \mathrm{m}$, sementara pada penelitian sebelumnya yang hanya menggunakan tangan dalam proses pemolesan memiliki nilai rerata $0,069 \mu \mathrm{m}^{4}$

Kelompok $\mathrm{C}$ berdasarkan penelitian ini memiliki nilai kekasaran permukaan rerata 0,088 $\pm 0,015 \mu \mathrm{m}$. Alasan pasta gigi dapat mengurangi nilai kekasaran permukaan sesuai dengan penelitian Tarbet dkk. (1984) menyatakan pasta gigi yang memiliki tingkat abrasif rendah dapat memoles permukaan gigi tiruan. Pisani dkk. (2010) setelah melakukan percobaan pengaruh tingkat abrasif pasta gigi terhadap kekasaran permukaan resin akrilik, menyatakan pasta gigi yang memiliki kandungan silika memiliki efek pemolesan pada permukaan basis gigi tiruan. ${ }^{10}$ Walaupun ukuran partikel pasta gigi lebih kecil dibandingkan bahan poles kelompok A dan kelompok B yang mana menjadi kelebihan dari pasta gigi, jumlah bahan abrasif yang terdapat pada pasta gigi lebih sedikit dibandingkan kelompok A dan kelompok $\mathrm{B}$, hal ini menjadikan kemampuan abrasif pasta gigi rendah sehingga efektifitas saat pemolesan berkurang.

Hasil uji LSD (Least Significant Different) (tabel 3) menunjukkan adanya perbedaan yang bermakna antara kelompok A dengan kelompok B dengan nilai $\mathrm{p}=0,0001(\mathrm{p}<0,05)$, kelompok A dengan kelompok $\mathrm{C}$ dengan nilai $\mathrm{p}=0,032(\mathrm{p}<0,05)$ dan kelompok $\mathrm{B}$ dengan kelompok $\mathrm{C}$ dengan nilai $\mathrm{p}=$ $0,0001(\mathrm{p}<0,05)$. Berdasarkan hal tersebut dapat dilihat secara statistik kelompok B menghasilkan nilai kekasaran permukaan paling baik dibandingkan kelompok A dan kelompok C, sedangkan kelompok C menghasilkan nilai kekasaran permukaan yang lebih baik dibandingkan kelompok A. Kelompok B yaitu cangkang telur memiliki kelebihan utama dibanding bahan lain, berupa jumlah bahan abrasif tertinggi dibandingkan bahan lain yaitu kandungan kalsium karbonat berkisar 94-98,2\%. ${ }^{14}$ Kelebihan lain berupa pemrosesan penghalusan menggunakan ball-mill yang diperlama, juga terbukti dapat menurunkan ukuran partikel cangkang telur, sehingga ukuran partikel rerata 
cangkang telur menjadi 2,21 $\mu \mathrm{m}^{12}$ Kedua kelebihan tersebut menjadikan proses pemolesan menjadi efisien dibandingkan bahan poles A dan B.

Secara klinis, nilai kekasaran permukaan yang diterima dibidang kedokteran gigi adalah kurang dari 0,2 $\mu \mathrm{m} .{ }^{4,5,15}$ Berdasarkan hal tersebut, kelompok A, B dan C telah memenuhi syarat nilai kekasaran permukaan untuk digunakan sebagai basis gigi tiruan. Ketiga bahan tersebut memiliki kelebihan dan kekurangan masing masing, pada kelompok A dengan menggunakan bahan poles pumis, merupakan bahan yang paling banyak digunakan untuk resin akrilik karena telah terbukti dapat mengurangi nilai kekasaran permukaan dibawah nilai $0,2 \mu \mathrm{m}$, akan tetapi memiliki kekurangan ketersediaan bahan yang hanya dapat ditemukan pada tempat penjualan tertentu dan tidak dapat diolah sendiri. Kelompok B yaitu cangkang telur memiliki kelebihan berupa ketersediaan bahan yang tergolong melimpah berdasarkan data dari badan pusat statistik, apabila bahan ini dimanfaatkan, tidak hanya dapat mengurangi limbah yang dapat mencemari lingkungan, berupa pencemaran air dan pencemaran udara, bahan ini juga dapat menghasilkan nilai ekonomis di masyarakat, akan tetapi cangkang telur masih memiliki kekurangan, yaitu, dalam pengolahan cangkang telur yang telah disederhanakan dibandingkan penelitian sebelumnya, masih perlu dilakukan penelitian lebih lanjut dalam hal pengolahan bahan tersebut. Kelompok $\mathrm{C}$ memiliki kelebihan berupa bahan ini dapat dengan mudah dijumpai dimanapun oleh karena umumnya masyarakat menggunakan bahan ini, serta dapat menghasilkan nilai kekasaran yang lebih baik dibandingkan kelompok A, akan tetapi bahan pasta gigi ini dalam mengurangi nilai kekasaran permukaan masih belum lebih baik dibandingkan bahan cangkang telur.

\section{DAFTAR PUSTAKA}

1. McCabe JF, Walls AWG. Applied dental materials. $9^{\text {th }}$ ed. London: Blackwell Munksgaard, 2008: 109-21.

2. Zhang X, Zhu B, Lin K, Chang J. Mechanical and thermal properties of denture PMMA reinforced with silanized borate whiskers. Dent Mater J 2012; 31: 903-8.

3. Gungor H, Gundogdu M, Duymus ZY. Investigating of the effect of different polishing techniques on the surface roughness of denture base and repair material. J Prosthet Dent 2014; 112: 1272-7.

4. Onwubu SC, Vahed A, Singh S, Kanny KM. Reducing the surface roughness of dental acrylic resins by using an eggshell abrasive material. J Prosthet Dent 2016; 117(2): 310-14.
5. Al-Kheraif AAA. The effect of mechanical and chemical polishing techniques on the surface roughnes of heat-polymerized and visible light polymerized acrylic denture base resin. Saudi Dent J 2014; 26: 56-62.

6. Ahmad AS. Evaluation and compare between the surface roughness of acrylic resin polished by pumice, white sand and black sand. J of Kerbala University 2011; 9: 49-54.

7. Turhan Ş, Gunduz L. Determination of specific activity of 226Ra, 232Th and $40 \mathrm{~K}$ for assessment of radiation hazards from Turkish pumice samples. Journal of Environmental Radioactivity 2008; 99: 332-42.

8. Anusavice KJ, Shen C, Rawls HR. Phillips' science of dental materials. $12^{\text {th }}$ ed. New Delhi: Elsevier Saunders, 2013: 92-100, 231-253.

9. Saleha, Halik M, Annisa N, Sudirman, Subaer. Sintesis dan Karakterisasi Hidroksiapatit dari Nanopartikel Kalsium Oksida (CaO) Cangkang Telur Untuk Aplikasi Dental Implan. Prosiding Pertemuan Ilmiah XXIX HFI Jateng \& DIY, Yogyakarta 2015, 124-7.

10. Pisani MX, et al. Evaluation of the abrasiveness of dentifrices for complete dentures. Journal of Prosthodontics 2010 25; 19: 369-73.

11. Hanna BA. Al-Majeed AEA. Abdulrazaak W. Effect of different dental materials on the surface roughness of acrylic resin (A comparative in vitro study). Marietta Daily Journal 2008; 5: 281-5.

12. Wu SC, Hsu HC, Hsu SK, Chang YC, Ho WF. Synthesis of hydroxyapatite from eggshell powders through ball milling and heat treatment. J. Asian Ceram Soc 2015; 198: 1-6.

13. Manappalil JJ. Basic dental material $3^{\text {th }}$ ed. India :Jaypee Brothers Medical Publisher, 2010: 381384, 391-9, 404-8.

14. Murakami FS, Rodrigues PO, Campos CMT de, Silva MAS. Physicochemical study of $\mathrm{CaCO} 3$ from egg shells. Cienc Tecnol Aliment 2007: 27 :658-62.

15. Hilgenberg SP, Orellana-Jimenez EE, SepûlvedaNavarro WF, Arana-Correa BE, Alves DCT, Campanha NH. Evaluation of surface physical properties of acrylic resins for provisional prosthesis. Material Research 2008; 11(3): 257 60 . 